\title{
THE EFFECT OF POSTURE ON ADDED HEART SOUNDS
}

\author{
BY \\ PHILIP RODIN* AND BERNARD TABATZNIK \\ From the Department of Medicine, The Johns Hopkins Hospital, Baltimore, Maryland, U.S.A. \\ Received June 18, 1962
}

The value of change of posture in discriminating between the various added heart sounds has not been generally recognized. Moreover, apart from Evans' study in 1943, the influence of heart failure on the results has received little attention. Thayer (1909) stated that the physiological third heart sound was rarely heard in the erect posture, and Boyer, Eckstein, and Wiggers (1940) could record the sound more commonly in recumbent than in sitting subjects. Evans (1943) also found that the physiological third sound usually disappeared when the upright posture was adopted whereas the third sound associated with heart failure usually remained audible. The atrial sound disappeared in 31 of 33 patients, mostly with coronary arterial disease or hypertension, when the erect posture was assumed (Engelbertz, 1953), and in 9 of 18 patients when sitting upright with the feet down (Parry and Mounsey, 1961). Mitral opening snaps persisted in the erect posture but the interval between the second sound and the snap was usually increased (Schölmerich and Gehl, 1951; and Surawicz, 1957).

In the present study we have investigated the effect of posture on the atrial sound, physiological and pathological third heart sounds, quadruple rhythm, pulmonary and aortic early systolic ejection sounds, and mitral opening snaps. In addition, some observations on the effect of change of posture on the widely-split second sound are reported in order to help assess the value of the manœuvre in differentiating this splitting from the mitral opening snap.

\section{METHOD}

Seventy-three subjects were examined by auscultation and phonocardiography, and their clinical details are given with the results. Some had more than one abnormal auscultatory sign. Nearly all of the recordings were obtained with the spectral phonocardiograph (McKusick, 1958). Heart sounds and electrocardiograms were recorded simultaneously on magnetic tape and then converted to spectral phonocardiograms. In these, frequency is displayed on the vertical axis and time on the horizontal axis, the intensity of sound being shown by the degree of blackness. Amplification was kept unchanged throughout each subject's recording and analysis. The recumbent record was obtained after the subject had rested in the supine position for ten minutes. Further records were made immediately after standing and at intervals up to five minutes later. In some cases additional phonocardiograms were made with the subject sitting with legs dependent.

\section{RESULTS}

Atrial Sound. Sixteen patients had atrial sounds without third heart sounds. Nine had systemic hypertension (all with diastolic pressures over $100 \mathrm{~mm} . \mathrm{Hg}$ ), one having cardiac ischæmia also. Two patients had idiopathic cardiomyopathy, 1 had syphilitic aortic regurgitation and complete heart block, and 4 had pulmonary hypertension. Nine had been in heart failure but this was well controlled in 8 at the time of the recording. The P-G interval, measured from the onset of the $P$

* Present address-The London Hospital, London E.1. 
wave of the electrocardiogram to the beginning of the atrial sound, was between $0 \cdot 12-1 \cdot 17 \mathrm{sec}$. except in 1 patient with pulmonary hypertension in whom it measured 0.09 sec.

The effect of change of posture is shown in Table I. The atrial sound, even when very loud in the recumbent patient, disappeared in 12 subjects on standing. This occurrence was not always instantaneous. In a few patients the sound moved closer to the first heart sound in the initial 30 seconds and then disappeared. In 1 patient with systemic hypertension a small sound persisted close to the first sound and started after the onset of the $Q$ wave of the electrocardiogram, so that

TABLE I

Effect of Change of Posture on Atrial Sound

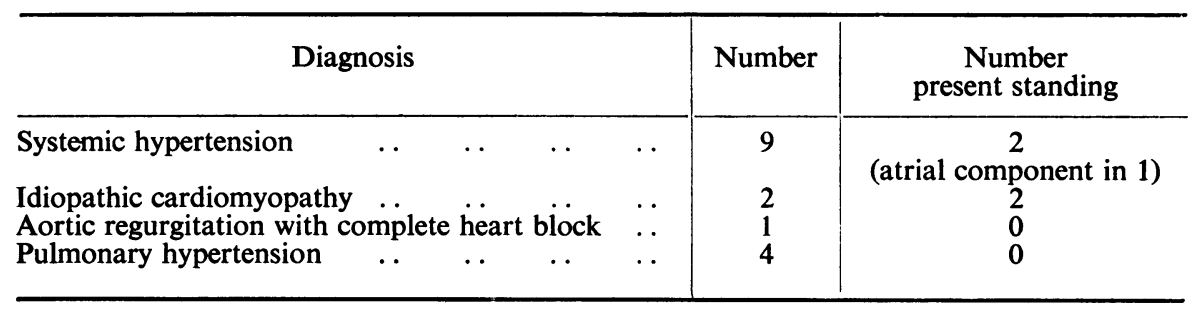

it could now properly be called an atrial component of the first heart sound (Kincaid-Smith and Barlow, 1959). In the remaining 3 patients (1 with systemic hypertension and cardiac ischæmia, and the 2 with idiopathic cardiomyopathy) the atrial sound persisted after standing for five minutes, but was closer to the first sound, although still starting before the onset of the $Q$ wave. After standing exercise, an atrial sound returned in 3 and an atrial component appeared in 1 of 4 patients with systemic hypertension in whom the atrial sound had disappeared on standing (Fig. 1 and 2).

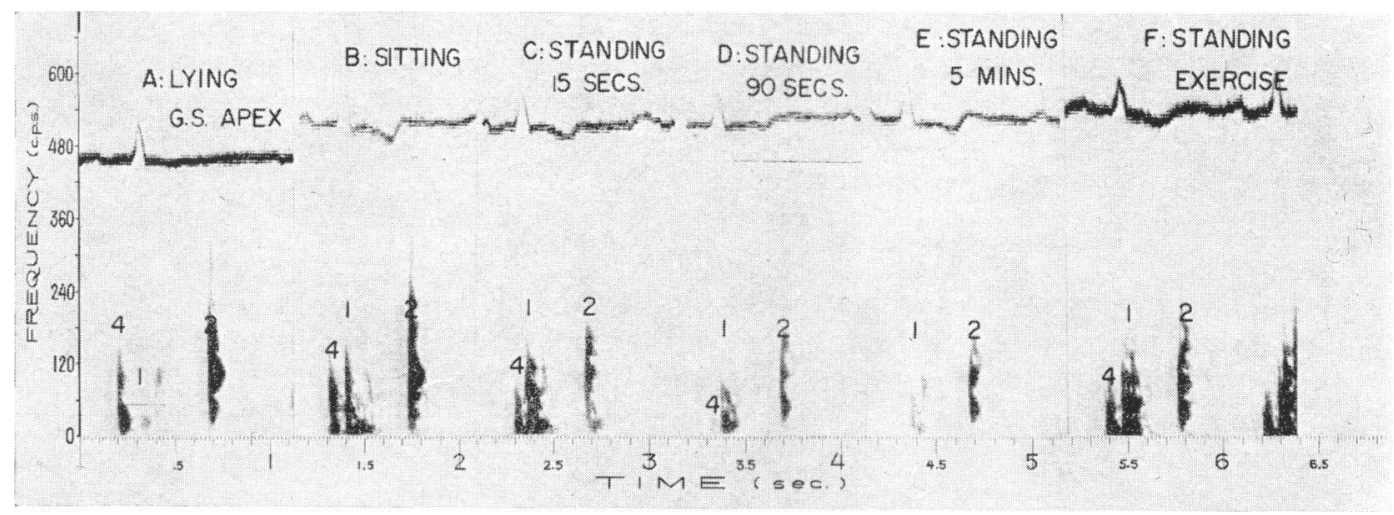

FIG. 1.-A hypertensive man, aged 41, with atrial sound. On mecamylamine. (A) Recumbent, loud atrial sound (4) seen. B.P. $200 / 120 \mathrm{~mm}$. Hg. Rate 65 . (B) Sitting, loud atrial sound present but closer to first sound. B.P. $175 / 110 \mathrm{~mm}$. Hg. Rate 67 . (C) Standing $15 \mathrm{sec}$., smaller and still closer atrial sound seen. B.P. $160 / 110 \mathrm{~mm}$. Hg. Rate 70 . (D) Standing $90 \mathrm{sec}$., atrial sound has become tiny atrial component of first sound. B.P. $160 / 100 \mathrm{~mm}$. Hg. Rate 70 . (E) Standing $5 \mathrm{~min}$., no atrial sound present. B.P. $160 / 100 \mathrm{~mm}$. Hg. Rate 67. (F) After standing exercise loud atrial sound reappears in spite of further fall in B.P. to $140 / 85 \mathrm{~mm}$. Hg. Rate 73. 1 and $2=$ first and second heart sounds.

A fall in blood pressure on standing occurred in only 2 patients with systemic hypertension receiving antihypertensive therapy, in both of whom the sound disappeared: one of these was the patient in poorly controlled heart failure. Most of the other patients showed a slight rise in blood pressure on standing. No significant change in heart rate or $\mathrm{P}-\mathrm{R}$ interval occurred with the change in posture. 
Recordings were made in 9 patients after they had been sitting with legs dependent for about one minute. The sound was still obvious in 8 , but it was often a little closer to the first heart sound. It disappeared in 6 of these when they stood up, persisted in 1, and in 1 it became a small atrial component of the first sound. Although we found the sound present while the patient was sitting more frequently than did Parry and Mounsey (1961), this may have been because our records were taken after the patient had been sitting only one minute whereas their patients had been sitting ten minutes.

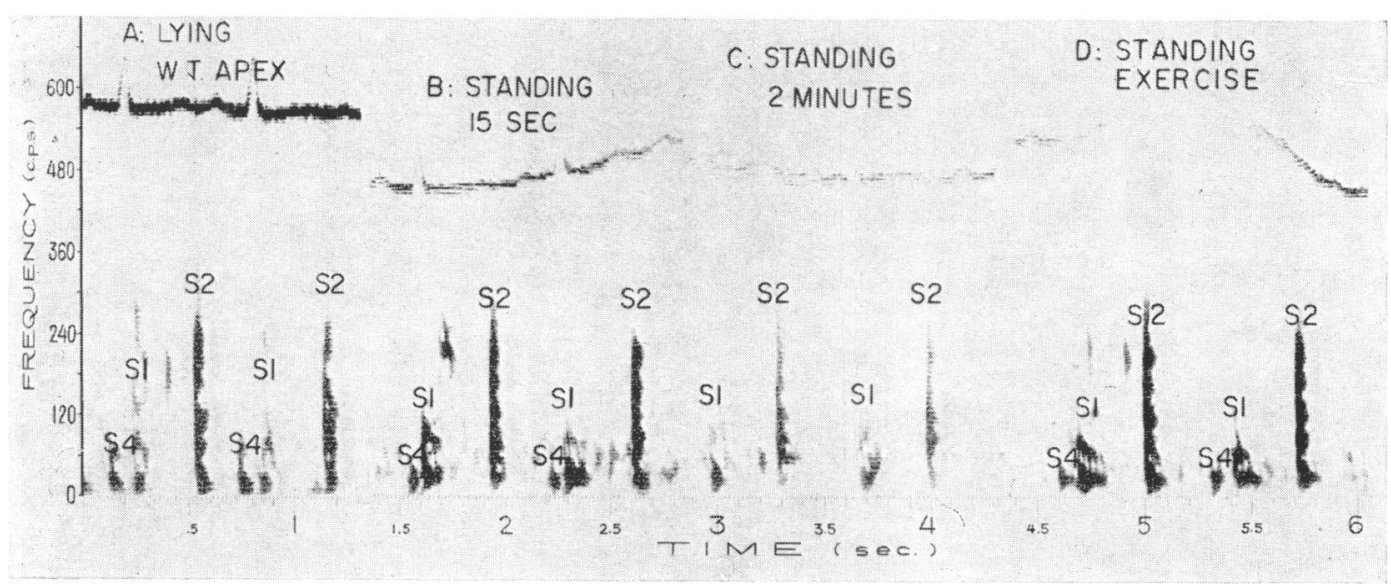

FIG. 2.-A hypertensive man, aged 48, with atrial sound. (A) Lying, loud atrial sound (S4) seen. B.P. $185 / 115 \mathrm{~mm}$. Hg. Rate 98. (B) Standing $15 \mathrm{sec}$., close atrial sound present. B.P. $200 / 120 \mathrm{~mm}$. $\mathrm{Hg}$. Rate 91. (C) Standing $2 \mathrm{~min}$., no atrial sound seen. B.P. $200 / 120 \mathrm{~mm}$. Hg. Rate 88. (D) After standing exercise atrial sound has returned. B.P. and rate unchanged.

The Third Heart Sound. Twenty subjects had third heart sounds without atrial sounds. The causes of the sound and the effect of change of posture are shown in Table II. The subjects with apparently physiological third sounds comprised 4 adolescent youths and 5 pregnant women. The sound disappeared within 30 seconds after standing in all 9, but was sometimes present in the sitting position with the feet down, although occurring a little later in diastole (Fig. 3).

Mitral regurgitation was present in 5 patients, aged 19 to 30 years: 2 had severe pure mitral regurgitation and in both the sound was well heard in the erect posture, but occurred later in diastole; of these patients 1 subsequently had a plication operation, and after this there was a late soft third sound that disappeared when she stood up (Fig. 4). Two patients had mild mitral regurgitation and associated mild aortic regurgitation. In one the sound persisted on standing but was softer and

TABLE II

Effect of Change of Posture on Third Heart Sound

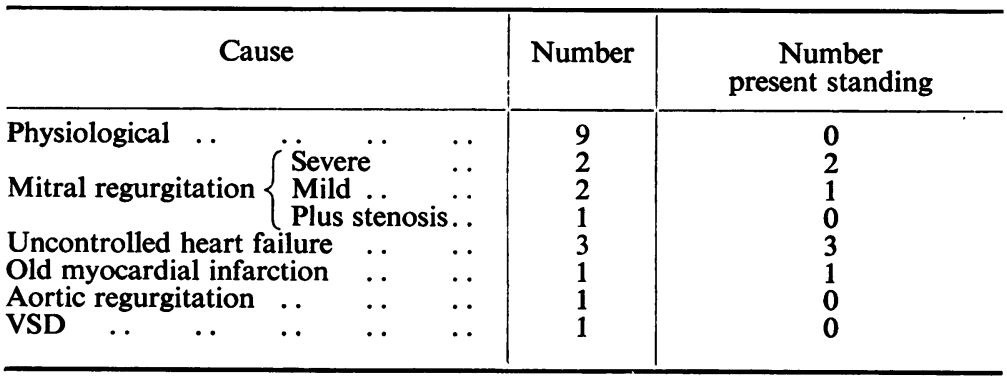




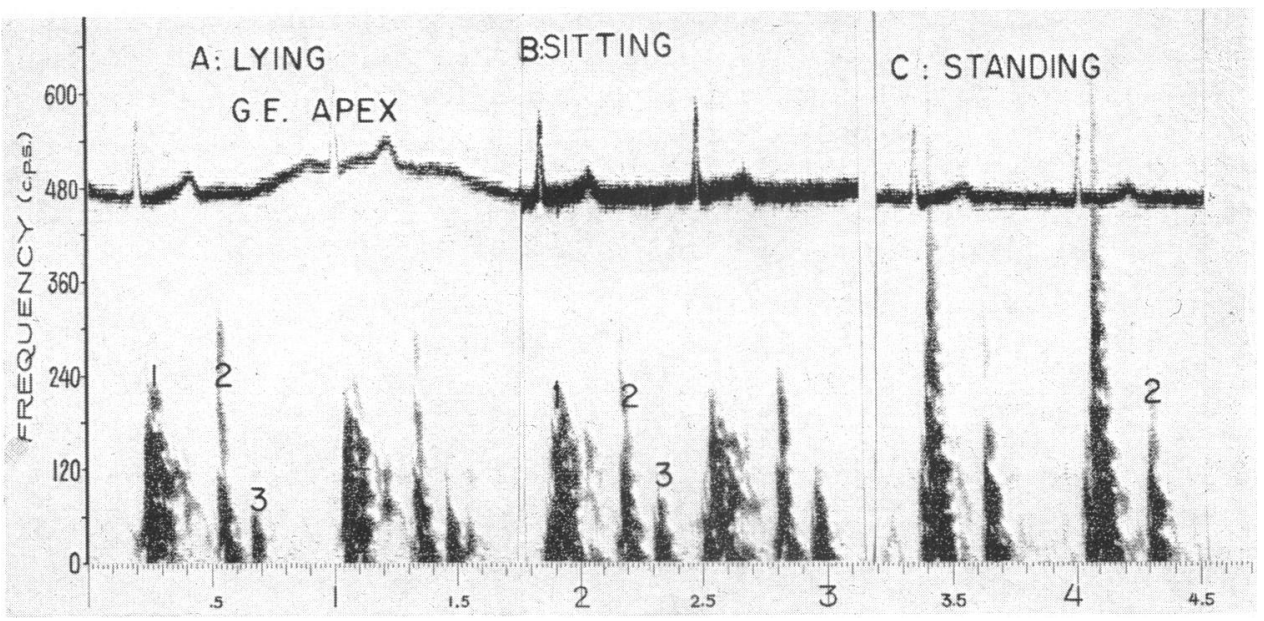

FIG. 3.-A normal boy, aged 15. (A) Lying, physiological third heart sound (3) present. (B) Sitting, sound occurs later. (C) Standing, sound has gone. Rate: lying 75, sitting 94, standing 91 . B.P.: lying $120 / 75$, standing $125 / 85 \mathrm{~mm}$. $\mathrm{Hg}$.

later, and in the other it disappeared. The remaining patient had mixed mitral regurgitation and stenosis. Trans-septal left heart catheterization showed a mean left atrial pressure of $26 \mathrm{~mm}$. $\mathrm{Hg}$ and an end-diastolic gradient across the mitral valve of $15 \mathrm{~mm}$. $\mathrm{Hg}$. The left atrial pressure pulse analysis was thought to be in the borderline range between stenosis and regurgitation. In this patient the sound disappeared on standing but the presystolic murmur became louder. In 3 patients, aged 50, 50, and 38 years, with uncontrolled congestive heart failure due to hypertension, ischæmic heart disease, and aortic regurgitation respectively, the sound persisted on standing. It was delayed in only one of them, whose failure was the least severe. In one patient examined again after the failure was brought under control, the sound no longer persisted on standing (Fig. 5).

One patient, a man aged 41 years, had suffered a myocardial infarction four years previously

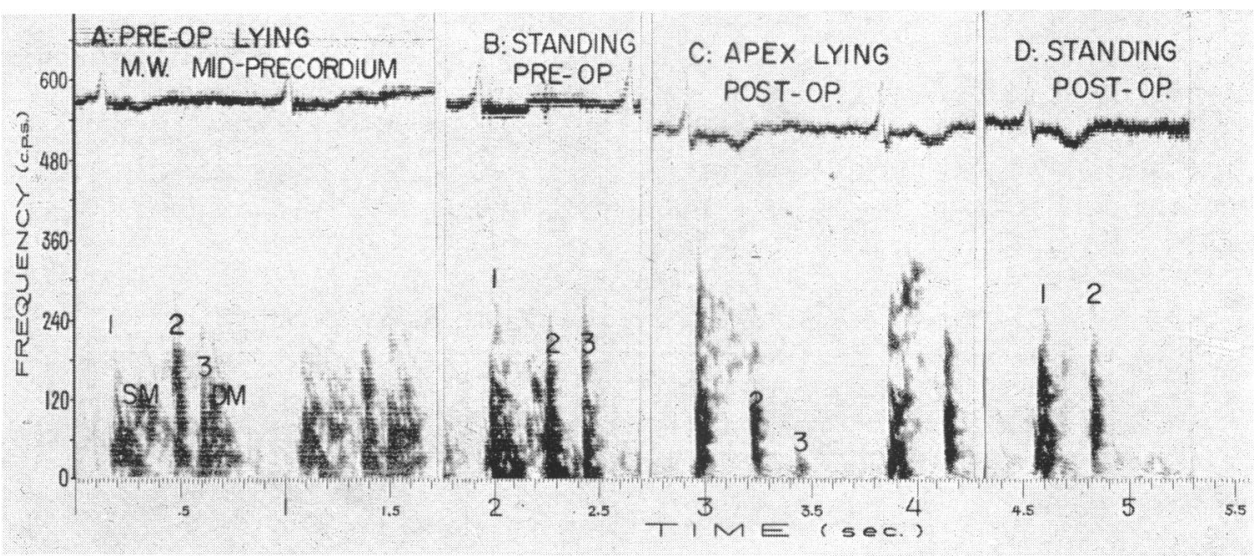

FIG. 4.-A woman, aged 27, with severe mitral regurgitation and atrial fibrillation. (A) Lying, third sound (3) followed by short mid-diastolic murmur (DM). (B) Standing $5 \mathrm{~min}$., loud but later third sound still present. (C) and (D) Three weeks following plication of mitral valve. Soft and later third sound present lying but not standing. 


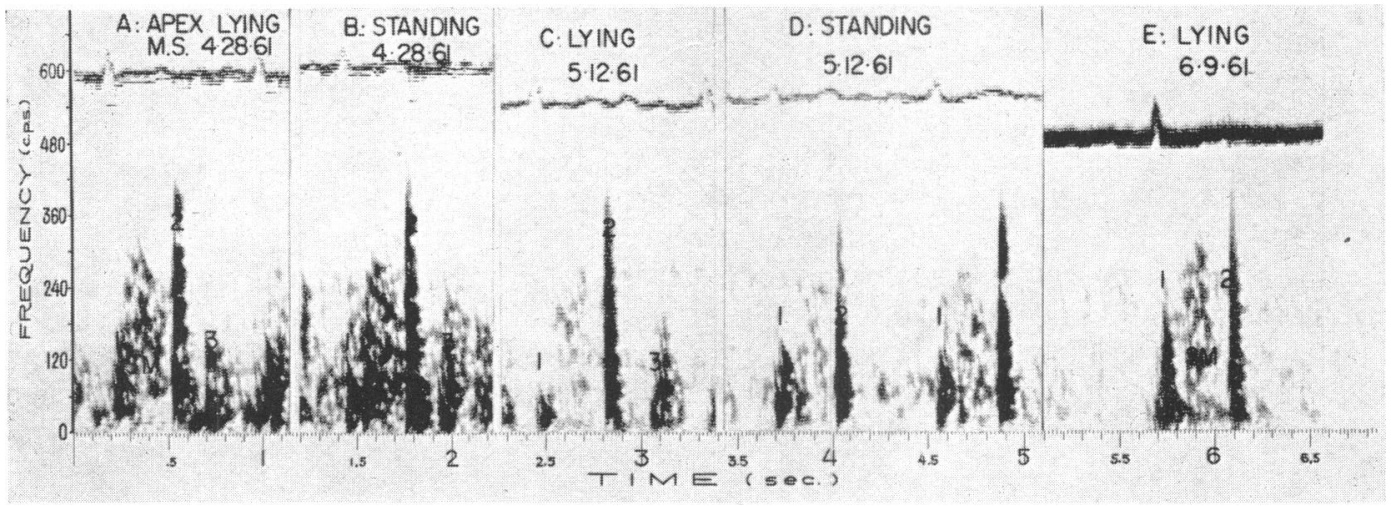

FIG. 5.-A woman, aged 50, with hypertension and congestive heart failure. (A) and (B) When heart failure uncontrolled, third sound (3) persists on standing (clarity of record partially obscured by muscle tremor). B.P.: lying 190/115; standing 190/110 mm. Hg. Rate 75 lying and standing. (C) and (D) Two weeks later when heart failure fairly well controlled. Third sound still present lying but occurs later and now disappears on standing. B.P.: lying 175/120, standing $170 / 120 \mathrm{~mm}$. Hg. Rate: lying 67 , standing 70 .

(E) One month later when failure fully controlled. No third sound present even when recumbent.

with subsequent angina pectoris. He was on long-term anticoagulant therapy. A recent electrocardiogram showed S-T depression in leads I, II, III, and V6, and a small $r$ wave in V4 (three years before this lead showed a large $Q$ wave). A loud third sound persisted when he stood up (Fig. 6). He was symptom-free apart from occasional angina, and cardioscopy showed only a slightly enlarged left ventricle and no hilar congestion. Of the remaining 2 patients, both aged 19 years, 1 had severe
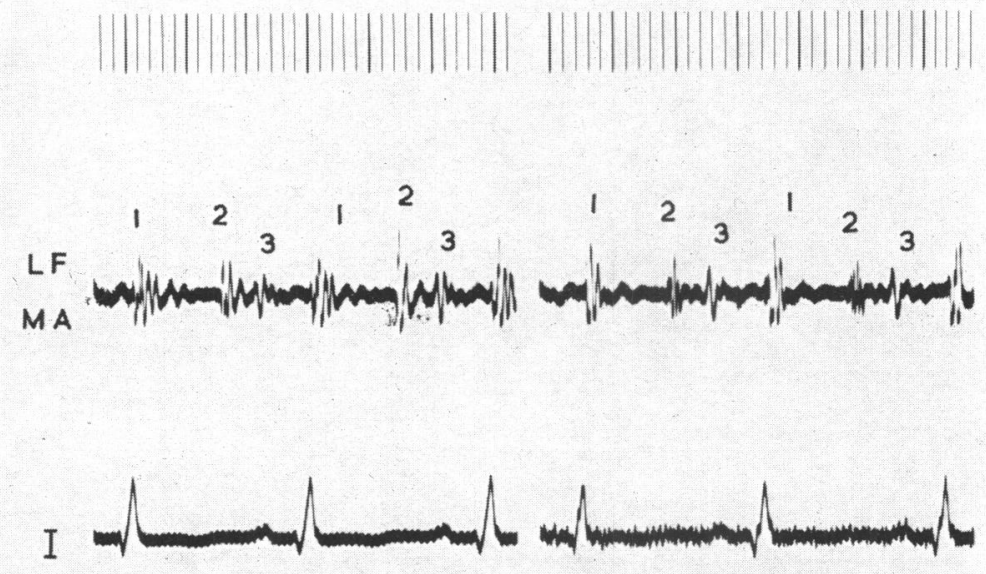
A. LYING.
B. STANDING $5 \mathrm{MIN}$ :

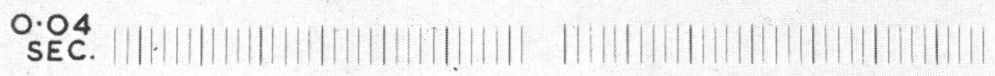

FIG. 6.-A man, aged 41, with old myocardial infarction and cardiac ischæmia. (A) Recumbent, third sound (3) seen in low frequency record. B.P. 140/90 mm. Hg. Rate 100 . (B) Standing 5 min., third sound still obvious. B.P. 145/95 mm. Hg. Rate 100. 
aortic regurgitation and the other Marfan's syndrome and a mild ventricular septal defect. Neither was in heart failure and the sound disappeared in both on standing.

In all cases only minor changes in blood pressure occurred with the change in posture. In most there was little change in heart rate, but in a few a slight tachycardia occurred on standing.

Quadruple Rhythm. Twenty subjects had both third and atrial sounds. Clinical details and the effect of change of posture are shown in Table III. Fig. 7 and 8 illustrate quadruple rhythms that disappeared and persisted respectively. From Table III it can be seen that both sounds remained on standing in 7 patients with moderate or severe heart failure which was only poorly controlled. Case 9, in whom both sounds persisted, had had severe heart failure, but this seemed well controlled at the time of the recording: he did, however, have gross cardiomegaly with functional mitral regurgitation. When the sounds persisted the third was usually slightly delayed and the atrial sound usually closer to the first sound.

TABLE III

Effect of Change of Posture on Quadruple Rhythm

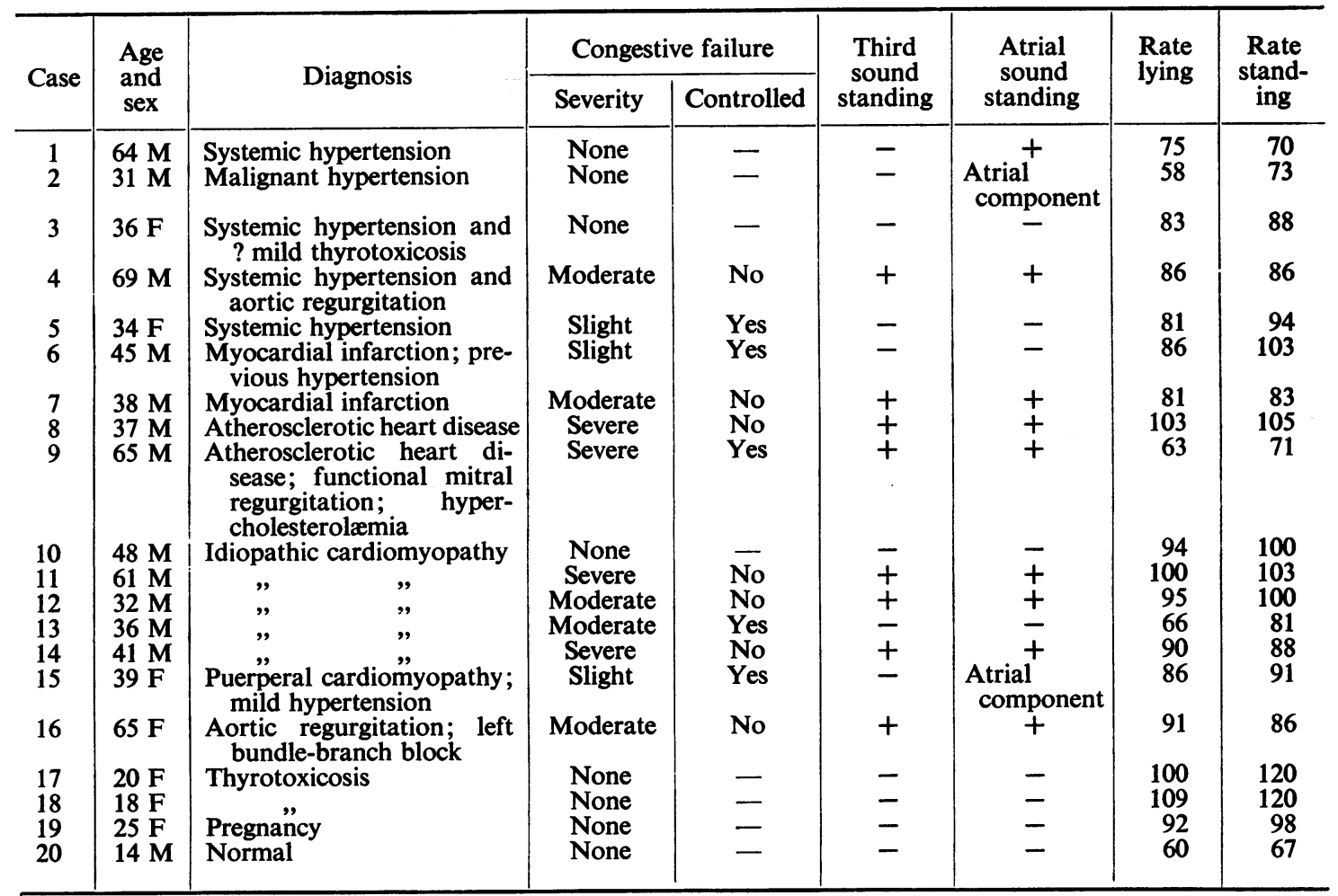

In Cases 1, 2, and 15 (Table III) the third sound disappeared, but the atrial persisted, although it moved closer to the first sound in Case 1 and became an atrial component of the first sound in Cases 2 and 15. Case 2 was the only patient in whom there was an appreciable change in blood pressure when he stood up, the pressure falling from $210 / 140$ to $160 / 125 \mathrm{~mm}$. $\mathrm{Hg}$.

Early Systolic Ejection Sounds. Of 16 patients, 9 had pulmonary ejection sounds and 7 aortic. The sound was well heard on standing in every case and was often louder in this position (Fig. 9 and 10). No significant change in blood pressure occurred.

Mitral Opening Snaps. Five patients with mitral stenosis were studied. The results are shown in Table IV. The values for the 2 patients with atrial fibrillation were obtained by measuring the 


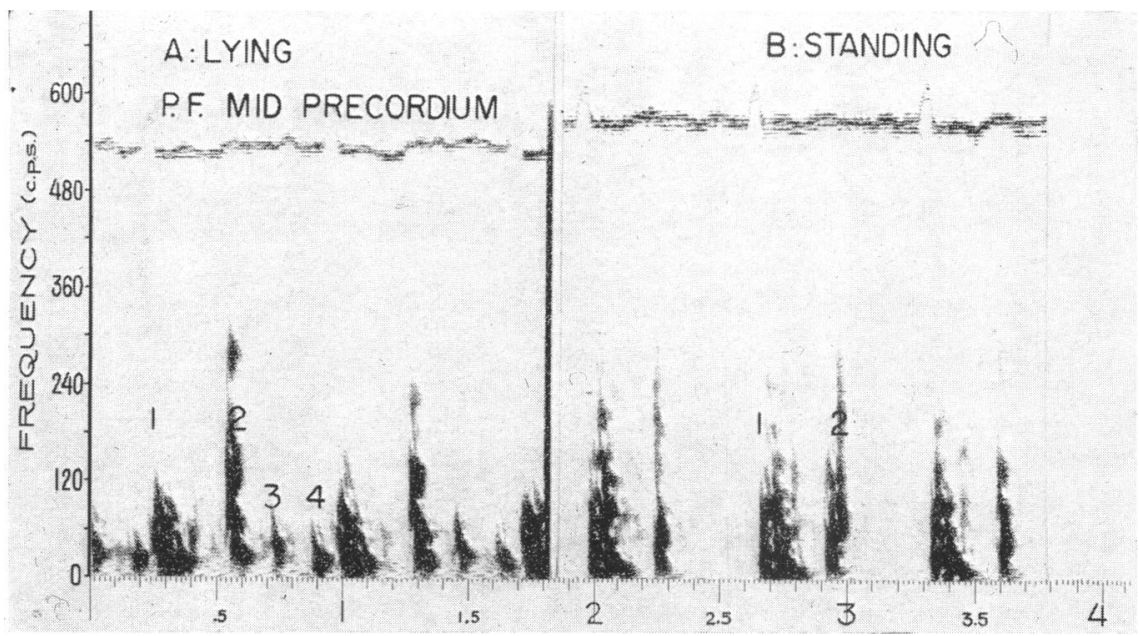

Fig. 7.-Case 3, a woman aged 36, with hypertension and possibly mild thyrotoxicosis. (A) Lying, third sound (3) and atrial sound (4) seen. B.P. $200 / 110 \mathrm{~mm}$. Hg. Rate 83 . (B) Standing, both third and atrial sounds have disappeared. B.P. 180/110 mm. Hg. Rate 88.

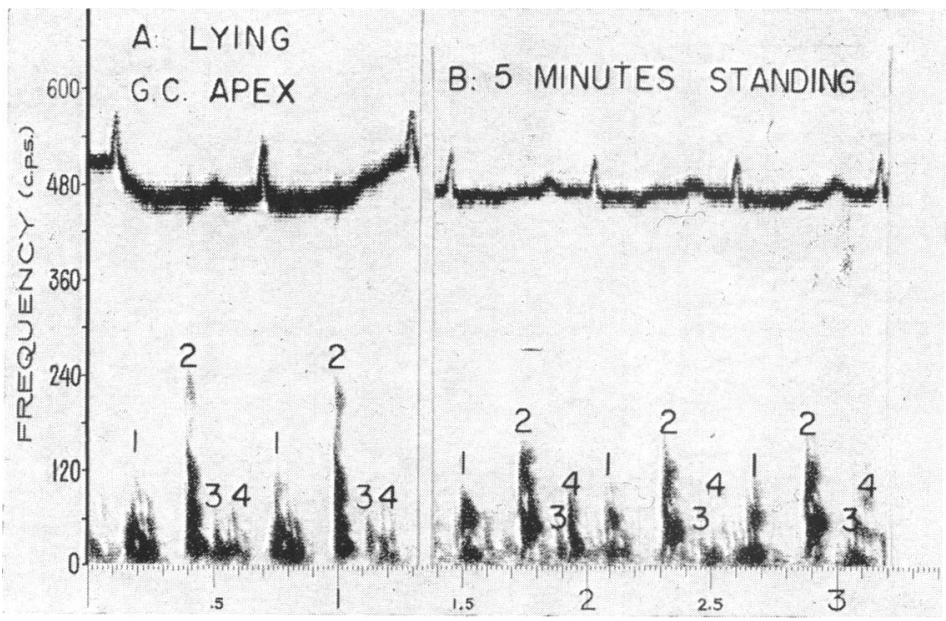

Frg. 8.-Case 8, a man aged 37, with severe congestive heart failure due to atherosclerotic heart disease (subsequently confirmed at necropsy). (A) Lying, third sound (3) and atrial sound (4) seen. B.P. $105 / 70 \mathrm{~mm}$. Hg. Rate 103. (B) Standing 5 min., both sounds still present. B.P. $110 / 80 \mathrm{~mm}$. Hg. Rate 105 


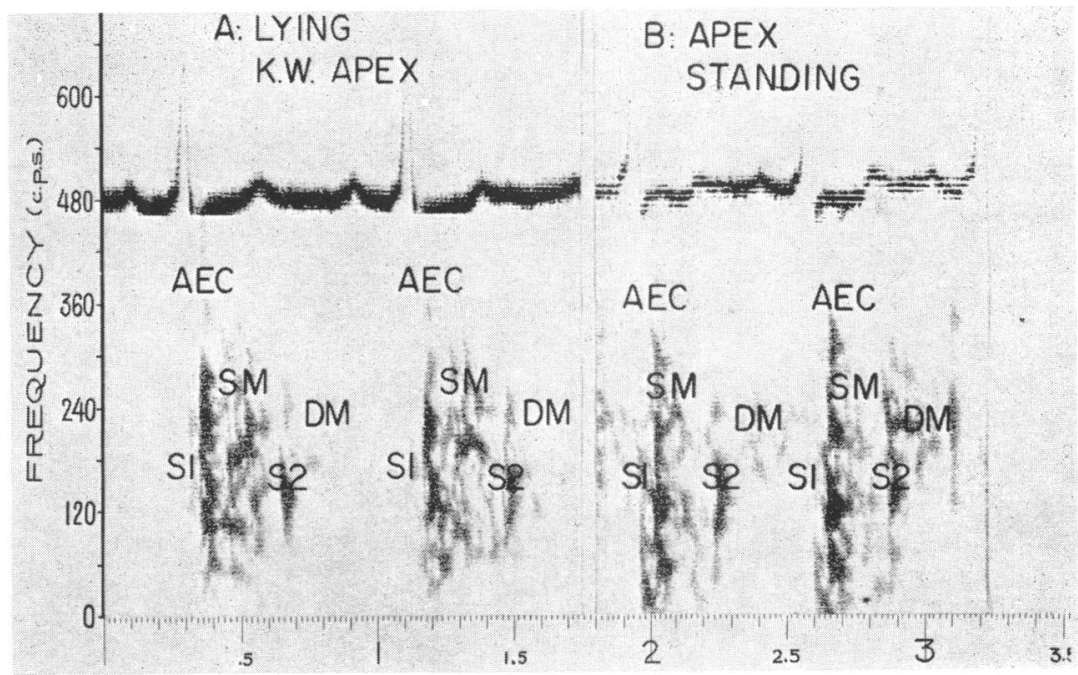

FIG. 9.-A man aged 36 with aortic regurgitation. (A) Lying, aortic ejection click (AEC) recorded at apex. Soft early diastolic murmur (DM) present in this area. (B) Standing, loud ejection click present and diastolic murmur more obvious. Heart rate lying 73 , standing 89 .

$\mathrm{S} 1$ and $\mathbf{S} 2=$ first and second heart sounds.

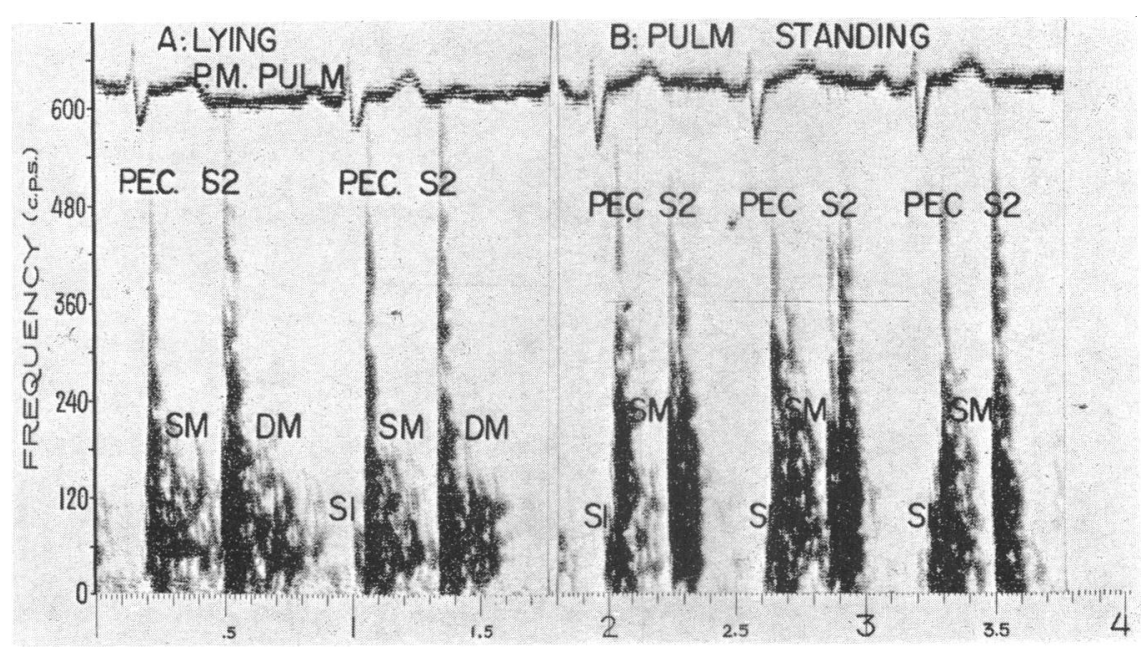

FIG. 10.-A girl aged 8, with idiopathic dilatation of pulmonary artery and pulmonary regurgitation. (A) Lying, loud pulmonary ejection click (PEC) and early diastolic murmur (DM) present. (B) Standing, ejection click still loud, but interestingly the diastolic murmur has disappeared. Heart rate lying 72, standing 92. 


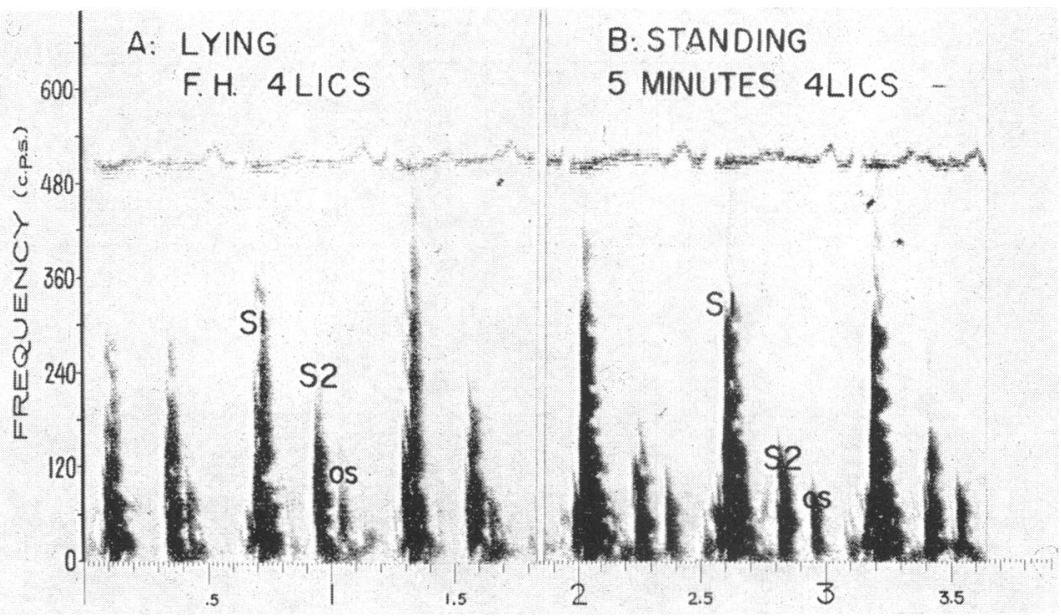

Fig. 11.-Case 23, a woman aged 35, with mitral stenosis. (A) Lying, opening snap (OS) occurs $0.08 \mathrm{sec}$. after second sound (S2). (B) Standing 5 min., opening snap present but now occurs $0 \cdot 12 \mathrm{sec}$. after second sound. Heart rate lying and standing 100 .

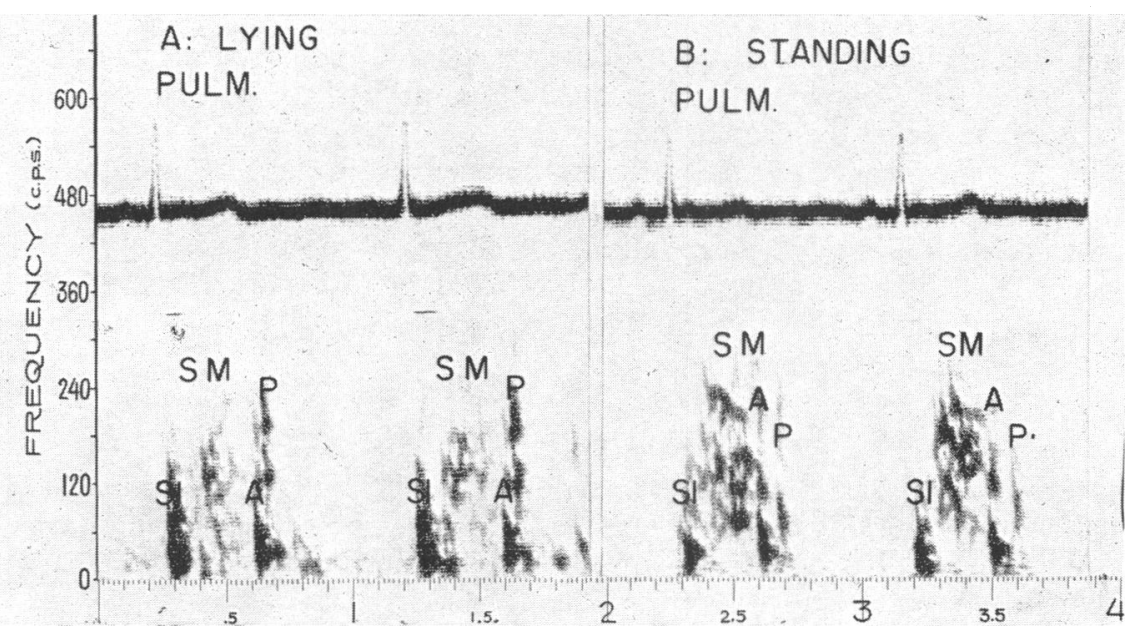

FIG. 12.-Case 26, a girl aged 19, with Marfan's syndrome and a mild ventricular septal defect. Split second sound when lying (A) becomes more widely split on standing (B), due to earlier occurrence of the aortic component of the second sound. The first sound to pulmonary component interval $(\mathrm{S} 1-\mathrm{P})$ is unchanged. Heart rate lying 60 , standing 65 . 
TABLE IV

Effect of Change of Posture on S2-OS Interval

\begin{tabular}{|c|c|c|c|c|c|}
\hline \multirow{2}{*}{ Case } & \multirow{2}{*}{$\begin{array}{l}\text { Age and } \\
\text { sex }\end{array}$} & \multicolumn{2}{|c|}{ S2-OS interval (sec.) } & \multirow{2}{*}{$\begin{array}{l}\text { Rate } \\
\text { lying }\end{array}$} & \multirow{2}{*}{$\begin{array}{c}\text { Rate } \\
\text { standing }\end{array}$} \\
\hline & & Lying & Standing & & \\
\hline $\begin{array}{l}21 \\
22 \\
23 \\
24 \\
25\end{array}$ & $\begin{array}{ll}45 & F \\
32 & F \\
34 & F \\
35 & F \\
47 & F\end{array}$ & $\begin{array}{l}0.06 \\
0.09 \\
0.08 \\
0.07 \\
0.10\end{array}$ & $\begin{array}{l}0.11 \\
0.11 \\
0.12 \\
0.09 \\
0.13\end{array}$ & $\begin{array}{r}\text { A.F. } \\
58 \\
100 \\
75 \\
\text { A.F. }\end{array}$ & $\begin{array}{r}\text { A.F. } \\
67 \\
100 \\
80 \\
\text { A.F. }\end{array}$ \\
\hline
\end{tabular}

A.F. $=$ Atrial fibrillation

TABLE V

Effect of Change of Posture on Widely Split Second Sound

\begin{tabular}{|c|c|c|c|c|c|c|c|c|}
\hline \multirow{2}{*}{ Case } & \multirow{2}{*}{$\begin{array}{l}\text { Age } \\
\text { and } \\
\text { sex }\end{array}$} & \multirow{2}{*}{ Diagnosis } & \multicolumn{2}{|c|}{ A-P lying (sec.) } & \multicolumn{2}{|c|}{ A-P standing (sec.) } & \multirow{2}{*}{$\begin{array}{l}\text { Rate } \\
\text { lying }\end{array}$} & \multirow{2}{*}{$\begin{array}{c}\text { Rate } \\
\text { stand- } \\
\text { ing }\end{array}$} \\
\hline & & & Least & Greatest & Least & Greatest & & \\
\hline 16 & $65 \mathrm{~F}$ & $\begin{array}{l}\text { Aortic regurgitation; left bundle- } \\
\text { branch block; congestive heart } \\
\text { failure }\end{array}$ & 0.05 & 0.05 & 0.06 & 0.06 & 91 & 86 \\
\hline $\begin{array}{l}26 \\
27\end{array}$ & $\begin{array}{l}19 \mathrm{~F} \\
41 \mathrm{M}\end{array}$ & $\begin{array}{l}\text { Mild VSD; Marfan's syndrome } \\
\text { Hypertension; controlled L.V. } \\
\text { failure }\end{array}$ & $\begin{array}{l}0.03 \\
0.06\end{array}$ & $\begin{array}{l}0.06 \\
0.08\end{array}$ & $\begin{array}{l}0.05 \\
0.07\end{array}$ & $\begin{array}{l}0.09 \\
0.08\end{array}$ & $\begin{array}{l}60 \\
63\end{array}$ & $\begin{array}{l}65 \\
75\end{array}$ \\
\hline 28 & $40 \mathrm{M}$ & $\begin{array}{l}\text { Repaired ASD; tiny defect still } \\
\text { present; mitral regurgitation }\end{array}$ & 0.06 & 0.07 & 0.05 & 0.06 & 79 & 100 \\
\hline $\begin{array}{l}29 \\
30 \\
31 \\
32 \\
33 \\
34\end{array}$ & $\begin{array}{l}18 \mathrm{~F} \\
32 \mathrm{M} \\
48 \mathrm{~F} \\
20 \mathrm{~F} \\
60 \mathrm{M} \\
47 \mathrm{~F}\end{array}$ & $\begin{array}{l}\text { Ostium primum } \\
\text { Pericardial and pleural effusions } \\
\text { Hypertension } \\
\text { Pregnant (8 months) } \\
\text { Pulmonary hypertension } \\
\quad, " \quad \text { " }\end{array}$ & $\begin{array}{l}0.06 \\
0.05 \\
0.04 \\
0.04 \\
0.04 \\
0.05\end{array}$ & $\begin{array}{l}0.06 \\
0.05 \\
0.05 \\
0.06 \\
0.05 \\
0.05\end{array}$ & $\begin{array}{l}0.06 \\
0.04 \\
0.03 \\
0.04 \\
0.03 \\
0.03\end{array}$ & $\begin{array}{l}0.06 \\
0.04 \\
0.04 \\
0.06 \\
0.05 \\
0.03\end{array}$ & $\begin{array}{r}100 \\
111 \\
57 \\
94 \\
88 \\
78\end{array}$ & $\begin{array}{r}120 \\
115 \\
59 \\
100 \\
79 \\
82\end{array}$ \\
\hline
\end{tabular}

second sound to opening snap intervals following equal diastolic periods lying and standing. The opening snap occurred later in the erect posture in all 5 (Fig. 11). No significant change in blood pressure accompanied the change in position.

Widely-split Second Sounds. Table V shows the results of change of posture on a widely-split second sound in 10 patients. In some cases the cause of the wide splitting was not apparent. All the records were taken during quiet respiration. A change of more than $0.01 \mathrm{sec}$. in the degree of splitting occurred in 2 patients only, Case 26 showing an increase (Fig. 12) and Case 34 a decrease in A-P interval. An appreciable change in blood pressure occurred in Case 27 only, being 255/135 lying and $180 / 120 \mathrm{~mm}$. Hg standing.

\section{Discussion}

The importance of venous return in the production and timing of diastolic gallop sounds has been demonstrated by observing the effect on them of venous pooling produced by venous occlusive cuffs applied to the limbs. This procedure often leads to their disappearance (Sloan and Wishart, 1953; and Leonard, Weissler, and Warren, 1958a; 1958b).

The assumption of the erect posture results in the shifting of blood from the central venous reservoir to the lower part of the body (Sjöstrand, 1952, 1953), a decreased pressure in the right atrium (Sieker and Gauer, 1957), and probably a decreased rate of ventricular filling (Kjellberg et al., 1950). It is, therefore, not surprising that in many cases diastolic gallop sounds disappeared when the subject stood up. Physiological third sounds always disappeared but third sounds in most 
patients with mitral regurgitation or poorly controlled heart failure persisted. It seems probable that with an initially high mean atrial pressure and volume any reduction of these that may occur on standing is less likely to result in a fall to a level required to abolish the sound although it may delay its onset. The persistence of the third sound in one patient (Fig. 6) with ischæmic heart disease but no evidence of heart failure or mitral regurgitation seems to indicate that reduction of ventricular distensibility may sometimes be of such importance in the production of the sound that the sound will persist on standing even though venous return is effectively reduced. Similar factors probably determine the response of an atrial sound to postural alterations.

Decrease in intensity of gallop sounds on standing is unlikely to be due simply to change of position of the heart in relation to the chest wall, for the following reasons. First, little change in cardiac position is to be expected on changing from the sitting to the standing position, yet in many cases where a sound was not heard in the standing subject it was heard when the subject was sitting. Second, atrial sounds were seen to migrate progressively towards the first sound before disappearing. Lastly, exercise by the subject in the standing posture sometimes resulted in the return of an obvious atrial sound (Fig. 1 and 2).

Our results show that a third heart sound or quadruple rhythm that persists on standing is unlikely to be of innocent origin. Its disappearance on standing, however, does not necessarily mean that it is benign, although the particular response to change of posture does seem to be related to the patient's clinical state and may serve as a useful guide to the adequacy of myocardial function. Thus when heart failure is controlled a third sound that previously persisted on standing may now disappear (Fig. 5).

We could not confirm the statement of Warren, Leonard, and Weissler (1958) that a right-sided atrial sound tends to persist when the patient is standing since it disappeared in all four of our patients with right-sided sounds due to pulmonary hypertension. They also state that examination of the patient in the erect posture may help to distinguish between pathological third sounds and mitral opening snaps. If the added sound disappears this is strong evidence against it being a snap, but as pathological third sounds also persist sometimes, the converse does not apply. Delay in the mitral opening snap is probably related to the fall in left atrial pressure, which occurs in the erect posture. Milnor and McGaff (1960) found an average fall in left atrial pressure of $10 \mathrm{~mm} . \mathrm{Hg}$ in 8 patients and Cardus, Mackinnon, and Wade (1958) found an average fall in pulmonary capillary venous pressure of $7 \mathrm{~mm}$. $\mathrm{Hg}$ in 16 patients with mitral stenosis when tilted from the horizontal to the semi-erect position.

Since the aortic ejection sound is usually well transmitted to the tricuspid and mitral areas it may be mistaken for the first heart sound and the real first sound, especially if soft, for an atrial sound (Wood, 1956; Leatham, 1958; and Warren et al., 1958). Auscultation of the patient in the standing posture may help to decide whether the additional sound is an atrial or ejection sound, as the former often disappears and the latter is, if anything, more obvious.

Several workers have commented on the effect of posture on the second heart sound. Wood (1958) stated that during the early post-operative phase following closure of an atrial septal defect fixed splitting of the second sound may be present when the patient is lying down, but the split becomes normal on sitting. Breen and Rekate (1960) noted that the wide expiratory splitting of the second sound, which is occasionally heard in healthy subjects, disappears on standing whereas that associated with atrial septal defects, mitral regurgitation, and right bundle-branch block persists. However, Surawicz (1957) presented phonocardiograms of 2 patients with atrial septal defect in which the splitting was appreciably less in the upright posture. Although he did not state how many of the 15 subjects he examined had a pathological cause for the splitting, he found a postural decrease in the interval between the two components of a widely split second sound in nearly all. He suggested that this manœuvre might be useful in differentiating widely-split second sounds from opening snaps, as the interval between the second sound and the opening snap was increased when the patient stood up. In our 10 patients, however, the effect of posture on the widely-split second sound was usually unimpressive, and in one patient the interval was increased, although respiratory 
variation was still obvious. As Mounsey (1953) pointed out, the fact that a split second sound and the opening snap can both be heard in most cases of mitral stenosis makes differentiation easier.

\section{SUMMARY}

The effect of change of posture on various added heart sounds was studied in 73 subjects by auscultation and phonocardiography. Atrial sounds disappeared in 12 of 16 patients shortly after standing. They sometimes reappeared after standing exercise. In the remaining 4, the atrial sounds all moved closer to the first sound, in 1 becoming an "atrial component". In the sitting patient, the sound was usually still obvious but a little closer to the first sound.

In standing subjects all physiological third sounds disappeared, but third sounds in most patients with mitral regurgitation or poorly controlled congestive heart failure persisted, although they sometimes occurred later in diastole. A third sound also persisted in a patient with ischæmic heart disease but no evidence of heart failure.

Quadruple rhythm persisted on standing in 8 of 20 patients. Seven of them were in poorly controlled heart failure and the eighth had well-controlled failure, gross cardiomegaly, and functional mitral regurgitation.

Diastolic gallop sounds that persist on standing are very unlikely to be physiological. The response of these sounds to change of posture may serve as a useful guide to the adequacy of myocardial function.

Pulmonary and aortic ejection sounds persisted on standing in all of 16 patients. As most atrial sounds disappear the effect of posture may help in difficult cases to distinguish atrial from ejection sounds.

Mitral opening snaps persisted in all of 5 patients in the standing posture but were delayed. In 8 of 10 patients with widely split second sounds no significant change in the degree of splitting occurred on standing, but in 1 it was increased and in 1 decreased.

\section{REFERENCES}

Boyer, N. H., Eckstein, R. W., and Wiggers, C. J. (1940). Amer. Heart J., 19, 257.

Breen, W. J., and Rekate, A. C. (1960). J. Amer. med. Ass., 173, 1326

Cardus, D., Mackinnon, J., and Wade, G. (1958). Brit. Heart J., 20, 233.

Engelbertz, P. (1953). Z. Kreisl.-Forsch., 42, 364.

Evans, W. (1943). Brit. Heart J., 5, 205.

Kincaid-Smith, P., and Barlow, J. (1959). Brit. Heart J., 21, 470.

Kjellberg, S. R., Lönroth, H., Rudhe, U., and Sjöstrand, T. (1950). Acta physiol. scand., $20,293$.

Leatham, A. (1958). Lancet, 2, 703.

Leonard, J. J., Weissler, A. M., and Warren, J. V. (1958a). Brit. Heart J., 20, 502.

(1958b). Circulation, 17, 1007.

McKusick, V. A. (1958). Cardiovascular Sound in Health and Disease. Williams and Wilkins, Baltimore.

Milnor, W. R., and McGaff, C. J. (1960). Circulation, 22, 790.

Mounsey, P. (1953). Brit. Heart J., 15, 135.

Parry, E., and Mounsey, P. (1961). Brit. Heart J., 23, 393.

Schölmerich, P., and Gehl, H. (1951). Z. Kreisl.-Forsch., 40, 211.

Sieker, H. O., and Gauer, O. H. (1957). Clin. Res. Proc., 5, 102.

Sjöstrand, T. (1952). Acta physiol. scand., 26, 312.

- (1953). Physiol. Rev., 33, 202.

Sloan, A. W., and Wishart, M. (1953). Brit. Heart J., 15, 25.

Surawicz, B. (1957). Circulation, 16, 422.

Thayer, W. S. (1909). Arch. intern. Med., 4, 297.

Warren, J. V., Leonard, J. J., and Weissler, A. M. (1958). Ann. intern. Med., 48, 580.

Wood, P. (1956). Diseases of the Heart and Circulation, 2nd ed. Eyre and Spottiswoode, London.

(1958). Brit. Heart J., 20, 267. 